\title{
MHD Mixed Convection Flow of a Casson Fluid over an Exponentially Stretching Surface with the Effects of Soret, Dufour, Thermal Radiation and Chemical Reaction
}

\author{
Kankanala Sharada, Bandari Shankar \\ Department of Mathematics, Osmania University, Hyderabad, India \\ Email: kankan.sharada@gmail.com
}

Received 29 July 2015; accepted 26 September 2015; published 29 September 2015

Copyright (C) 2015 by authors and Scientific Research Publishing Inc.

This work is licensed under the Creative Commons Attribution International License (CC BY). http://creativecommons.org/licenses/by/4.0/

\section{(c) (i) Open Access}

\begin{abstract}
The present study deals with MHD (magneto hydrodynamics) mixed convection flow of a Casson fluid over an exponentially stretching sheet with the effects of Soret and Dufour, thermal radiation, chemical reaction. The governing partial differential equations are converted into ordinary differential equations by using similarity transformations. These equations are then solved numerically by applying finite difference scheme known as the Keller Box method. The effects of various parameters on velocity, temperature and concentration profiles are presented graphically to interpret and the results are discussed.
\end{abstract}

\section{Keywords}

Casson Fluid, Magneto Hydrodynamics, Mixed Convection, Exponentially Stretching Surface, Soret and Dufour Effects, Thermal Radiation, Chemical Reaction

\section{Introduction}

The study of magneto hydrodynamics, boundary layer flow with heat and mass transfer from a stretching surface has many applications in industrial and engineering fields. Magnetic fields can be used to manage thermal energy in flowing electrically conducting polymers (Garnier [1]). After the pioneering studies of Sakiadas [2] and Crane [3], several researchers further investigate the problem of stretching sheet boundary layer flow to obtain thermal and kinematic behaviour by considering the various types of stretching velocity. Magyari and Keller [4] examine the similarity solutions of thermal boundary layer and flow over an exponentially stretching surface 
with an exponential temperature distribution. Numerical solution of boundary layer flow over an exponentially stretching sheet including thermal radiation is investigated by Bidin and Nazar [5], and analytical study is investigated by Sajid and Hayat [6].

Casson fluid is one type of fluid model for non-Newtonian fluid, which has significant applications in polymer processing industries and biomechanics. Casson fluid can be defined as a shear thinning liquid which is presumed to have an infinite viscosity at zero rate of shear and a yield stress under which no flow occurs and zero viscosity at an infinite rate of shear. Casson fluid model is used in many foodstuffs and biological materials, especially blood. It describes the steady shear stress, shear rate behaviour of blood. Merill et al. [7] and Mc Donald [8] investigate the behaviour of blood. Nadeem et al. [9] investigate the magneto hydrodynamic boundary layer flow of Casson fluid over exponentially permeable shrinking sheet. Casson fluid over an unsteady stretching surface is analyzed by Mukhopadhyay [10]. The application of the minimal energy phenomenon to a Casson fluid is studied by John L. McGregor [11]. A similarity solution technique for mixed convection heat transfer from an exponentially stretching surface with the effect of viscous dissipation is investigated by Partha et al. [12]. Recently Dual pal [13] studies mixed convection heat transfer in the boundary layers over an exponentially stretching surface including magnetic field. The effects on mixed free forced convective and mass transfer steady, laminar boundary layer flow over a vertical plate with temperature dependent viscosity are presented by Kafoussias and Williams [14].

The mass flux created by temperature gradient is known as thermal diffusion (Soret) effect. The energy flux caused by concentration differences is known as diffusion thermo (Dufour) effect. The Soret effect has been utilized for medium molecular weight (eg. $\mathrm{N}_{2}$ and air) and isotope separation. These effects have several applications in engineering problems. Here a survey conducted by Dursunkaya and Worek [15] on Soret and Dufour effects in transient and steady natural convection from a vertical surface. The combined effects of thermal diffusion and diffusion thermo over stretching surface with free convective heat and mass transfer are investigated by Afify [16]. T. Hayat [17] describes the effects of Soret and Dufour on magneto hydrodynamic flow of Casson fluid. Alam and Rahman [18] study the Dufour and Soret effects on mixed convection flow with variable suction.

Several researchers have studied the effects of thermal radiation, and these include that Pramanik [19] investigates Casson fluid flow and heat transfer over an exponentially stretching surface in the presence of thermal radiation and porous medium. Numerical analysis of magneto hydrodynamic stagnation point flow of a Casson fluid includes thermal radiation discussed by Shateyi and Marewo [20]. Anur Ishak [21] present the magneto hydrodynamic boundary layer flow over an exponentially stretching sheet with the effect of radiation. Swathi Mukhopadhyay [22] investigate Casson fluid flow and heat transfer on an unsteady stretching surface subjected to suction/blowing with the effect of thermal radiation. Recently effects of mass transfer on magneto hydrodynamic flow of Casson fluid with chemical reaction are studied by S.A. Shehzad and T. Hayat [23].

This paper provides the solution to the problem of fluid flow, heat and mass transfer of a Casson fluid over an exponentially stretching surface by considering the effect of Soret and Dufour, thermal radiation, chemical reaction by adopting the Keller Box method.

\section{Mathematical Formulation}

Consider two-dimensional steady, laminar, incompressible MHD flow of a Casson fluid over a vertical exponential surface stretching with velocity $U_{w}(x)=a \mathrm{e}^{\frac{x}{L}}$, temperature distribution $T_{w}(x)$ and concentration distribution $C_{w}(x)$ moving through a fluid of constant temperature $T_{\infty}$ and concentration $C_{\infty}$ as shown in Figure 1. The $\mathrm{x}$-axis is oriented about the vertical surface in the upward direction and $\mathrm{y}$-axis is normal to it. A magnetic field is applied in the direction perpendicular to the stretching surface. The magnetic Reynolds number is taken to be small enough such that the induced magnetic field is negligible. The rheological equation of state for an isotropic and incompressible flow of a Casson fluid can be written as:

$$
\begin{gathered}
\tau_{i j}=\left(\mu_{b}+\frac{P_{y}}{\sqrt{2 \pi}}\right) 2 e_{i j} \text { when } \pi>\pi_{c} \\
\tau_{i j}=\left(\mu_{b}+\frac{P_{y}}{\sqrt{2 \pi_{c}}}\right) 2 e_{i j} \text { when } \pi<\pi_{c}
\end{gathered}
$$




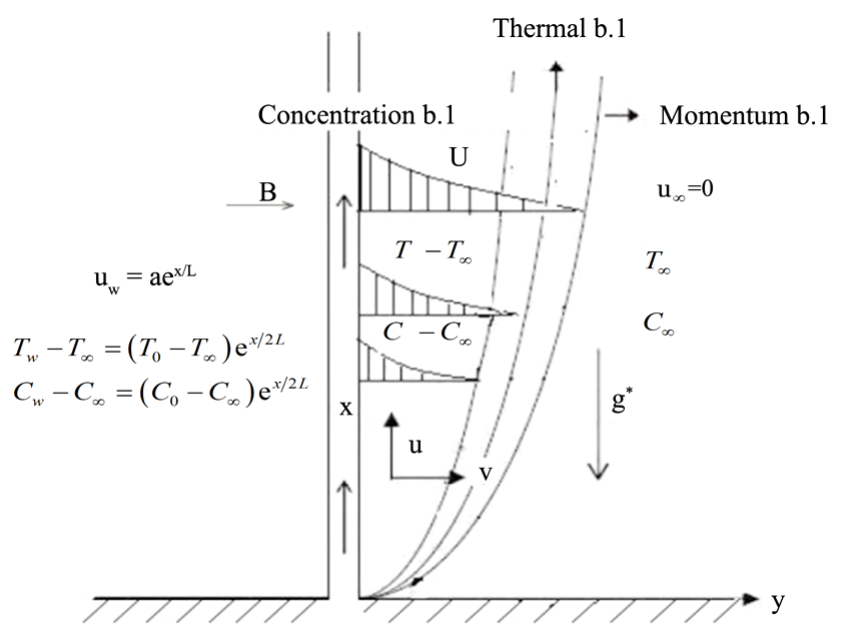

Figure 1. Physical model and coordinate system.

$P_{y}$ is known as yield stress of the fluid, mathematically expressed as $P_{y}=\frac{\mu_{b} \sqrt{2 \pi}}{\beta}, \mu_{b}$ is known as plastic dynamic viscosity of the non Newtonian fluid, $\pi$ is the product of the component of deformation rate with itself (i.e. $\pi=e_{i j} e_{i j}$ ) and $\tau_{i j}$ is the $(i, j)$ th component of the stress tensor.

Considering $u, v$ as velocity components in the directions of $x$ and $y$ respectively in the flow field. The governing equations of continuity, momentum, energy and concentration are given by

$$
\begin{gathered}
\frac{\partial u}{\partial x}+\frac{\partial v}{\partial y}=0 \\
u \frac{\partial u}{\partial x}+v \frac{\partial u}{\partial y}=v\left(1+\frac{1}{\beta}\right) \frac{\partial^{2} u}{\partial y^{2}}+g^{*}\left(\beta_{T}\left(T-T_{\infty}\right)+\beta_{C}\left(C-C_{\infty}\right)\right)-\frac{\sigma B^{2} u}{\rho} \\
u \frac{\partial T}{\partial x}+v \frac{\partial T}{\partial y}=\alpha \frac{\partial^{2} T}{\partial y^{2}}-\frac{1}{\rho c_{p}} \frac{\partial q_{r}}{\partial y}+\frac{v}{C_{p}}\left(1+\frac{1}{\beta}\right)\left(\frac{\partial u}{\partial y}\right)^{2}+\frac{D k_{T}}{C_{p} C_{s}} \frac{\partial^{2} C}{\partial y^{2}} \\
u \frac{\partial C}{\partial x}+v \frac{\partial C}{\partial y}=D \frac{\partial^{2} C}{\partial y^{2}}+\frac{D K_{T}}{T_{m}} \frac{\partial^{2} T}{\partial y^{2}}-k\left(C-C_{\infty}\right) .
\end{gathered}
$$

where $\rho$ is the density of the fluid, $\sigma$ is the electrical conductivity, $v$ is the kinematic viscosity, $B$ is the magnetic induction, $\alpha$ is the thermal diffusivity, $D$ is the solutal diffusivity of the medium, $\beta_{T}$ and $\beta_{C}$ are the coefficient of thermal and solutal expansions, $\mu$ is the dynamic co-efficient of viscosity, $C_{p}$ and $C_{s}$ are the specific heat capacity and concentration susceptibility, $T_{m}$ is the mean fluid temperature, $K_{T}$ is the thermal diffusion ratio, $\gamma$ is the chemical reaction parameter and $\beta=\mu_{b} \sqrt{2 \pi_{c}} / P_{y}$ is the Casson parameter.

The boundary conditions considered are defined as:

$$
\begin{gathered}
u=U_{w}(x)=a \mathrm{e}^{\frac{x}{L}}, v=0, T=T_{w}=T_{\infty}+\left(T_{0}-T_{\infty}\right) \mathrm{e}^{\frac{x}{2 L}} \\
C=C_{w}=C_{\infty}+\left(C_{0}-C_{\infty}\right) \mathrm{e}^{\frac{x}{2 L}} \text { at } y=0 \\
u=0, T \rightarrow T_{\infty}, C \rightarrow C_{\infty} \text { as } y \rightarrow \infty
\end{gathered}
$$

where subscripts $w$ and $\infty$ indicate that conditions at the wall and at the external(outer) edge of the boundary layer respectively and $U_{w}(x)$ is the stretching velocity, $T_{w}(x)$ and $C_{w}(x)$ are the exponential temperature and concentration distribution respectively.

In above conditions " $a$ " is velocity parameter of the stretching surface, $T_{0}$ is temperature distribution pa- 
rameter, $C_{0}$ is the parameter of the concentration distribution in the stretching surface.

We introduce stream function $\psi$ as $u=\frac{\partial \Psi}{\partial y}, v=-\frac{\partial \psi}{\partial x}$ and define variables.

$$
\begin{gathered}
u=a \mathrm{e}^{\frac{x}{L}} f^{\prime}(\eta), \eta=\sqrt{\frac{a}{2 v L}} \mathrm{e}^{\frac{x}{2 L}} y, v=-\sqrt{\frac{a v}{2 L}} \mathrm{e}^{\frac{x}{2 L}}\left[f(\eta)+\eta f^{\prime}(\eta)\right] \\
T(x, y)=T_{\infty}+\left(T_{0}-T_{\infty}\right) \mathrm{e}^{\frac{x}{2 L}} \theta(\eta), C(x, y)=C_{\infty}+\left(C_{0}-C_{\infty}\right) \mathrm{e}^{\frac{x}{2 L}} \phi(\eta)
\end{gathered}
$$

By using the Rosseland approximation for radiative heat flux, $q_{r}$ is defined as:

$$
q_{r}=-\frac{4 \sigma^{*}}{3 K^{*} k} \frac{\partial T^{4}}{\partial y}
$$

where $\sigma^{*}$ is the Stephen Boltzman constant and $K^{*}$ is the mean absorption coefficient. Since the temperature differences within the flow field are assumed to be small, and then we linearize and expand $T^{4}$ into the Taylor series about $T_{\infty}$, which after neglecting higher order forms take the form.

$$
T^{4} \cong 4 T_{\infty}^{3} T-3 T_{\infty}^{4}
$$

To obtain similarity solutions, we assumed that the magnetic field is of the form $B(x)=B_{0} \mathrm{e}^{\frac{x}{L}}$ where $B_{0}$ is the constant magnetic field and $K(x)=K_{0} \mathrm{e}^{\bar{L}}$ is the exponential reaction, $K_{0}$ is constant.

With the help of above similarity transformations the governing equations are transformed in to

$$
\begin{gathered}
\left(1+\frac{1}{\beta}\right) f^{\prime \prime \prime}+f f^{\prime \prime}-2\left(f^{\prime}\right)^{2}+2 \lambda \mathrm{e}^{\frac{-3 X}{2}}(\theta+N \phi)-M f^{\prime}=0 \\
\left(1+\frac{4}{3} N r\right) \theta^{\prime \prime}+\operatorname{Pr}\left(f \theta^{\prime}-f^{\prime} \theta\right)+\operatorname{PrEce^{\frac {3X}{2}}}\left(1+\frac{1}{\beta}\right)\left(f^{\prime \prime}\right)^{2}+\operatorname{Pr} D_{f} \phi^{\prime \prime}=0 \\
\phi^{\prime \prime}+\operatorname{Sc}\left(f \phi^{\prime}-f^{\prime} \phi\right)+S c S r \theta^{\prime \prime}-S c \gamma \phi=0
\end{gathered}
$$

The corresponding boundary conditions are

$$
\begin{gathered}
\eta=0: f(0)=1, f^{\prime}(0)=1, \theta(0)=1, \phi(0)=1 \\
\eta \rightarrow \infty: f^{\prime}(\infty)=0, \theta(\infty)=0, \phi(\infty)=0
\end{gathered}
$$

where $X=\frac{X}{L}$ is the $X$-location, observing Equations (10), (11) in MHD mixed convection due to Casson fluid, the velocity and temperature profiles are not similar because the $x$ coordinate cannot be deleted from these equa tions. It is hard to proceed in this case. To reduce the difficulty of analysis, it was considered $X=\frac{X}{L}$ to find local similarity solutions for the governing equations. Now one can study the effects of different parameters on various profiles at any given $X$-location.

$M=\frac{2 \sigma B_{0}^{2} L}{\rho a}$ is the magnetic parameter, $\lambda=\frac{G r}{R e^{2}}$ is the mixed convection parameter, $R e=\frac{a L}{v}$ is the Reynolds number, $G r=\frac{g^{*} \beta_{T}\left(T_{0}-T_{\infty}\right) L^{3}}{v^{2}}$ is the Grashoff number, $N=\frac{\beta_{c}\left(C_{0}-C_{\infty}\right)}{\beta_{T}\left(T_{0}-T_{\infty}\right)}$ is the Buoyancy ratio, $\operatorname{Pr}=\frac{v}{\alpha}$ is the Prandtl number, $E c=\frac{a^{2}}{C_{p}\left(T_{0}-T_{\infty}\right)}$ is the Eckert number, $N r=\frac{4 \sigma^{*} T_{\infty}^{3}}{3 k k^{*}}$ is the Thermal radiation parameter, $D_{f}=\frac{D K_{T}\left(C_{0}-C_{\infty}\right)}{v C_{s} C_{p}\left(T_{0}-T_{\infty}\right)}$ is the Dufour number, $S r=\frac{D K_{T}\left(T_{0}-T_{\infty}\right)}{v T_{m}\left(C_{0}-C_{\infty}\right)}$ is the Soret number, $S c=\frac{v}{D}$ is the Schmidt number, $\gamma=\frac{K_{0} L}{a}$ is the chemical reaction parameter. 
The wall shear stress, heat and mass transfer coefficients with constant density are given by $\tau_{w}=\left(\mu_{b}+\frac{P_{y}}{\sqrt{2 \pi}}\right)\left(\frac{\partial u}{\partial y}\right)_{y=0}, q_{w}=-k\left(\frac{\partial T}{\partial y}\right)_{y=0}$ and $q_{m}=-D\left(\frac{\partial C}{\partial y}\right)_{y=0}$ where $k$ is the thermal conductivity. The dimensionless form of skin friction $C_{f}=\frac{2 \tau_{w}}{\rho U_{*}^{2}}$. Where $U_{*}$ is the characteristic velocity, the local Nusselt number $N u_{x}=\frac{x q_{w}}{k\left(T_{w}-T_{\infty}\right)}$, and local Sherwood number $S h_{x}=\frac{x q_{w}}{D\left(C_{w}-C_{\infty}\right)}$ are given by $C f_{x}=\frac{\sqrt{2} X}{\sqrt{R e_{x}}}\left(1+\frac{1}{\beta}\right) f^{\prime \prime}(0), N u_{x}=-\left(1+\frac{4}{3} N r\right) \sqrt{\frac{R e_{x} X}{2}} \theta^{\prime}(0)$ and $S h_{x}=-\sqrt{\frac{R e_{x}}{2}} \phi^{\prime}(0)$.

\section{Method of Solution}

The governing equations with boundary equations are solved numerically by using finite difference scheme known as Keller Box method which is described by Cebeci and Bradshaw [24]. This method involves the following steps:

Step 1: Reducing higher order ODEs (systems of ODES) in to systems of first order ODEs;

Step 2: Writing the systems of first order ODEs into difference equations using central difference scheme;

Step 3: Linearizing the difference equations using Newton's method and writing it in vector form;

Step 4: Solving the system of equations using block elimination method.

\section{Numerical Discussions}

To solve the above differential equations numerically, we adopt Matlab software. In this process the step size, $\Delta \eta=0.01$ is used to obtain numerical solution with five decimal place accuracy as the criterion of convergence. Table 1 shows that the comparison between wall temperature gradient $\theta^{\prime}(0)$ calculated by the present method and of Magyari and Keller for $\lambda=X=D_{f}=N r=S r=\gamma=N=M=S c=E c=0$ and $\beta \rightarrow \infty$. The numerical vales of $\left(1+\frac{1}{\beta}\right) f^{\prime \prime}(0),-\theta^{\prime}(0)$, and $-\phi^{\prime}(0)$ for the various values of $\lambda, X, D_{f}, N r, S r, \gamma, \beta$ are shown in Table 2.

\section{Results and Discussion}

In the present study, the following values are adopted for the numerical computations $N=0.5, D_{f}=0.03, S r=$ $0.5, \lambda=1.0, \operatorname{Pr}=1.0, M=1.0, S c=0.22, X=0.5, \gamma=0.1, \beta=0.5$. These values are used throughout the calculations unless otherwise mentioned.

Figure 2 shows that the non-dimensional velocity profile for different values of the mixed convection parameter $\lambda$. We have observed the results for both aiding flow and apposing flow. It illustrates that the dimensionless velocity increases, as the value of $\lambda$ increases. As $\lambda$ increases, the buoyancy effects increase and hence the fluid flow accelerates. In the case of mixed convection, temperature is low for aiding flow and more for

Table 1. Comparison of results for $-\theta^{\prime}(0)$ with previous published work.

\begin{tabular}{ccc}
\hline Pr & Magyari and Keller [4] & Present \\
\hline 0.5 & -0.59434 & -0.5946 \\
1.0 & -0.95478 & -0.9548 \\
3.0 & -1.86908 & -1.8691 \\
5.0 & -2.50014 & -2.5002 \\
8.0 & -3.24213 & -3.2423 \\
10.0 & -3.66038 & -3.6606 \\
\hline
\end{tabular}


Table 2. Effects of skin friction coefficient, heat and mass transfer coefficients for various values of $\lambda, X, D_{f}, N r, S r, \gamma$ and $\beta$.

\begin{tabular}{cccccccccc}
\hline$\Lambda$ & $X$ & $N r$ & $S r$ & $D_{f}$ & $\gamma$ & $B$ & $(1+1 / \beta)^{\prime \prime}(0)$ & $-\theta^{\prime}(0)$ & $-\Phi^{\prime}(0)$ \\
\hline 1.0 & 0.5 & 1.0 & 0.5 & 0.03 & 0.1 & 0.5 & -1.9167 & 0.6505 & 0.4246 \\
2.0 & 0.5 & 1.0 & 0.5 & 0.03 & 0.1 & 0.5 & -1.1259 & 0.7017 & 0.4560 \\
3.0 & 0.5 & 1.0 & 0.5 & 0.03 & 0.1 & 0.5 & -0.3918 & 0.7383 & 0.4797 \\
1.0 & 0.2 & 1.0 & 0.5 & 0.03 & 0.1 & 0.5 & -1.4607 & 0.6870 & 0.4431 \\
1.0 & 1.0 & 1.0 & 0.5 & 0.03 & 0.1 & 0.5 & -2.3684 & 0.5841 & 0.4044 \\
1.0 & 2.0 & 1.0 & 0.5 & 0.03 & 0.1 & 0.5 & -2.7091 & 0.3124 & 0.4054 \\
1.0 & 0.5 & 1.5 & 0.5 & 0.03 & 0.1 & 0.5 & -1.8828 & 0.5637 & 0.4371 \\
1.0 & 0.5 & 3.0 & 0.5 & 0.03 & 0.1 & 0.5 & -1.8174 & 0.4204 & 0.4593 \\
1.0 & 0.5 & 4.6 & 0.5 & 0.03 & 0.1 & 0.5 & -1.7766 & 0.3429 & 0.4722 \\
1.0 & 0.5 & 1.0 & 1.0 & 0.03 & 0.1 & 0.5 & -1.9071 & 0.6527 & 0.3779 \\
1.0 & 0.5 & 1.0 & 3.0 & 0.03 & 0.1 & 0.5 & -1.8687 & 0.6612 & 0.1894 \\
1.0 & 0.5 & 1.0 & 5.0 & 0.03 & 0.1 & 0.5 & -1.8309 & 0.6692 & -0.0019 \\
1.0 & 0.5 & 1.0 & 0.5 & 1.0 & 0.1 & 0.5 & -1.8774 & 0.5596 & 0.4387 \\
1.0 & 0.5 & 1.0 & 0.5 & 2.0 & 0.1 & 0.5 & -1.8372 & 0.4601 & 0.4530 \\
1.0 & 0.5 & 1.0 & 0.5 & 3.0 & 0.1 & 0.5 & -1.7967 & 0.3535 & 0.4675 \\
1.0 & 0.5 & 1.0 & 0.5 & 0.03 & 0.15 & 0.5 & -1.9203 & 0.6496 & 0.4394 \\
1.0 & 0.5 & 1.0 & 0.5 & 0.03 & 0.25 & 0.5 & -1.9266 & 0.6480 & 0.4670 \\
1.0 & 0.5 & 1.0 & 0.5 & 0.03 & 0.35 & 0.5 & -1.9326 & 0.6466 & 0.4927 \\
1.0 & 0.5 & 1.0 & 0.5 & 0.03 & 0.1 & 0.8 & -1.6085 & 0.6370 & 0.4171 \\
1.0 & 0.5 & 1.0 & 0.5 & 0.03 & 0.1 & 1.0 & -1.4976 & 0.6315 & 0.4143 \\
1.0 & 0.5 & 1.0 & 0.5 & 0.03 & 0.1 & 1.5 & -1.3415 & 0.6233 & 0.4101 \\
\hline & & & & & & & & & \\
\hline
\end{tabular}

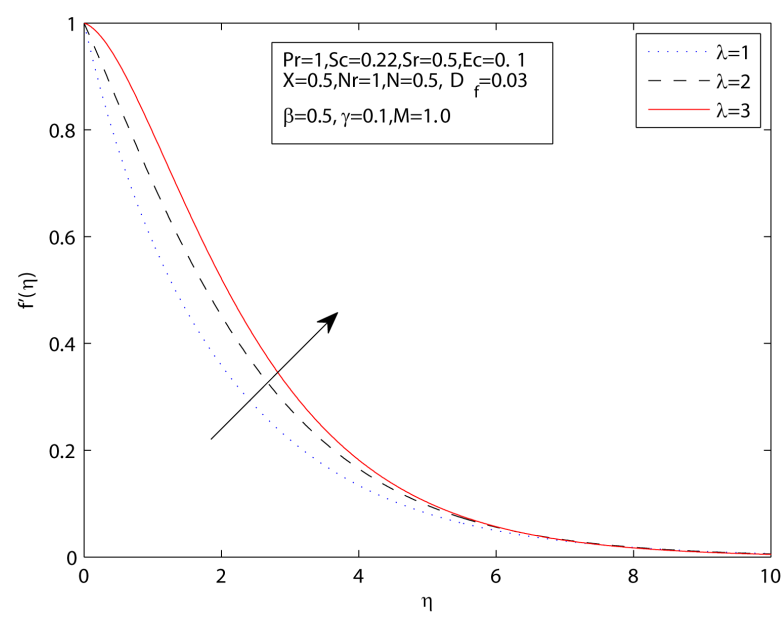

Figure 2. Velocity profiles for various values of mixed convection parameter $\lambda$.

opposing flow. As $\lambda$ increases, the convection cooling effect increases and therefore temperature decreases. Figure 3, Figure 4 reveal that the dimensionless temperature and concentration reduces with increase of $\lambda$.

Figure 5 depicts the effects of Casson parameter $\beta$ on dimensionless velocity profiles for impermeable stretching surface. The velocity is found to decrease with the increasing Casson parameter $\beta$. Figure 6, Figure 7 present the temperature and concentration profiles for Casson parameter $\beta$. It shows that the both temperature and concentration profiles decreasing with increasing of $\beta$. Figure 8 illustrates the velocity profile for different values of the magnetic parameter $M$. The presence of magnetic field reduces the momentum boundary layer 


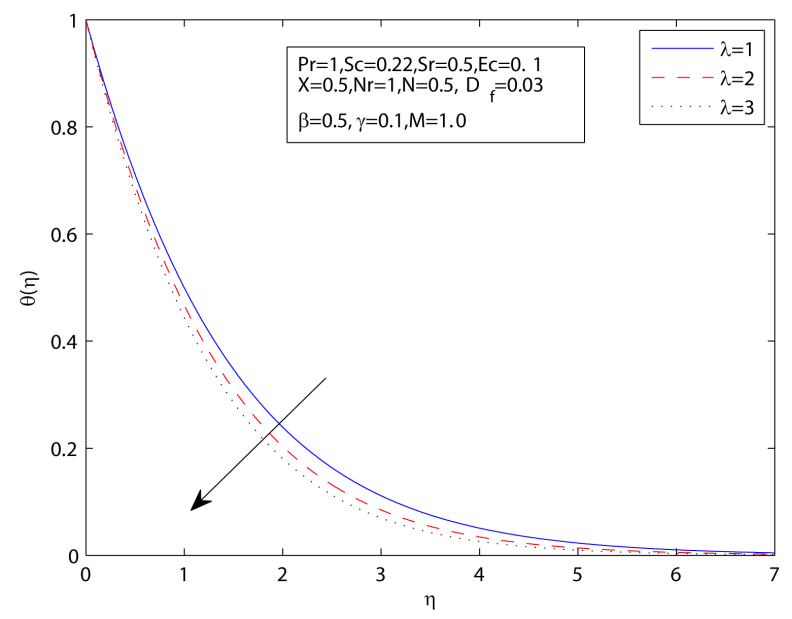

Figure 3. Temperature profiles for various values of mixed convection parameter $\lambda$.

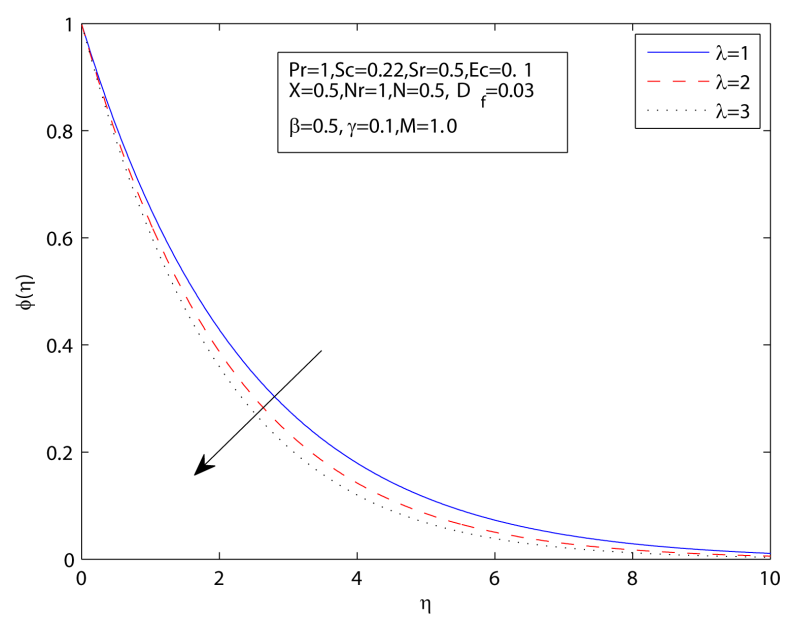

Figure 4. Concentration profiles for various values of mixed convection parameter $\lambda$.

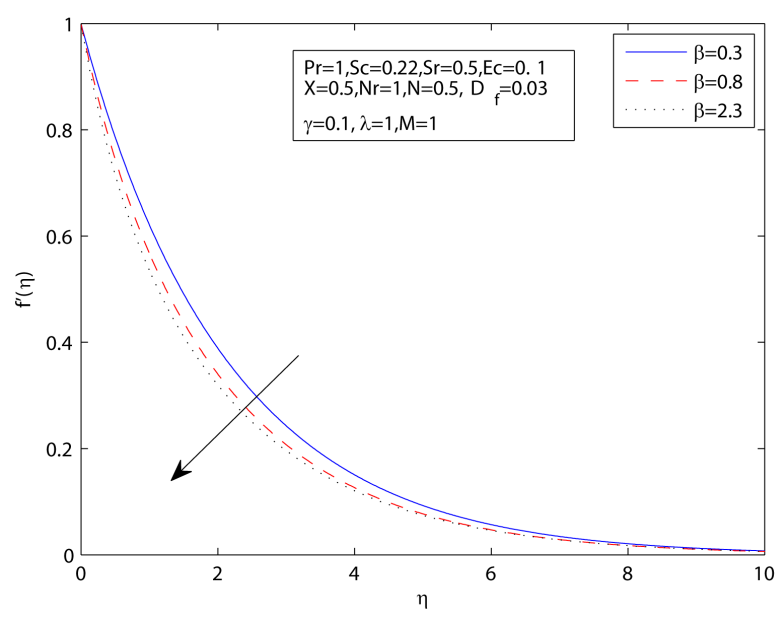

Figure 5. Velocity profiles for various values of Casson parameter $\beta$. 


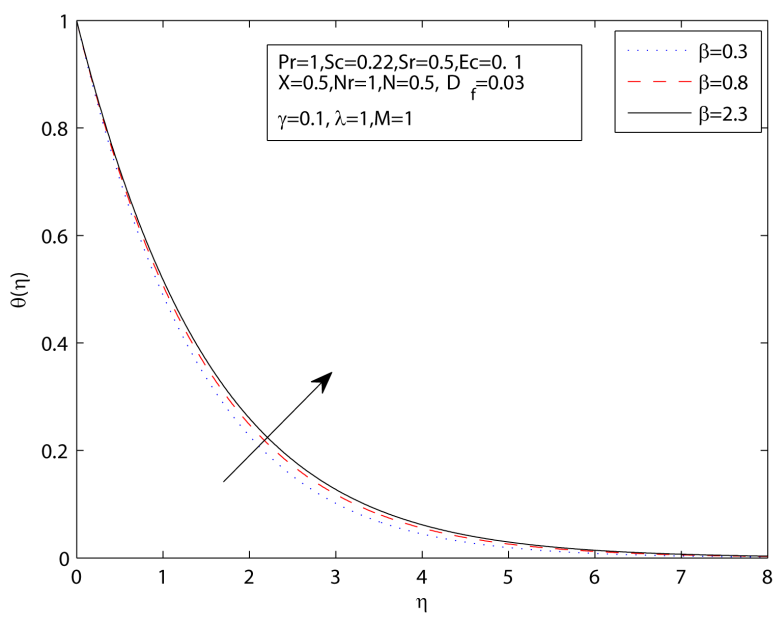

Figure 6. Temperature profiles for various values of Casson parameter $\beta$.

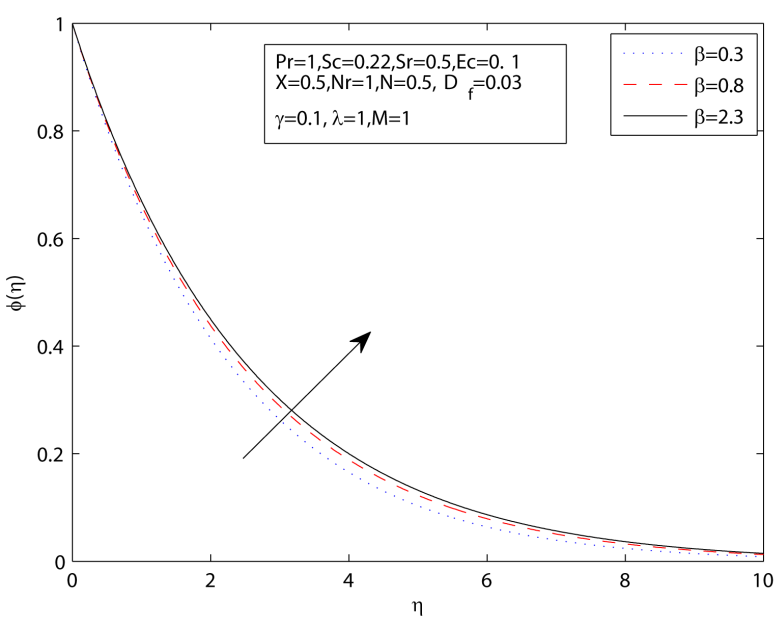

Figure 7. Concentration profiles for various values of Casson parameter $\beta$.

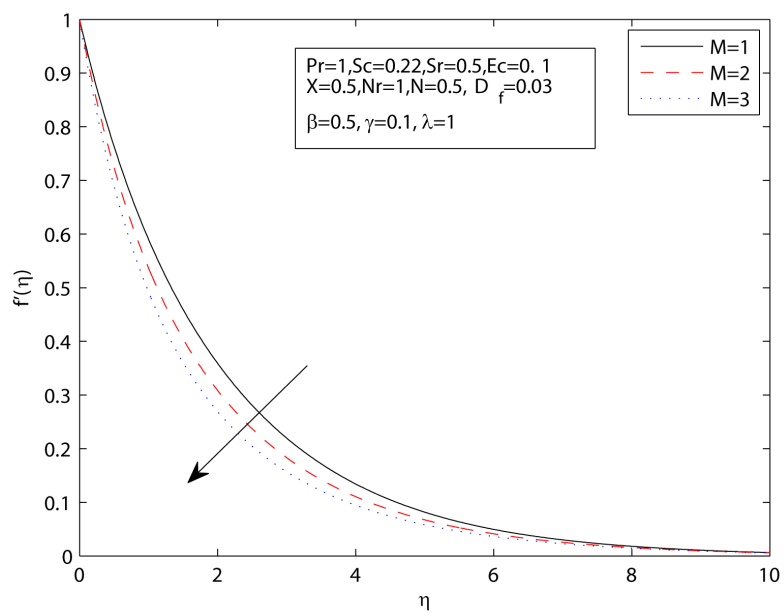

Figure 8. Velocity profile for various values of magnetic parameter $M$. 
thickness. Thus the velocity decreases as the magnetic parameter increases.

Increasing the values of the $E c$ generates heat in the fluid due to frictional heating. Figure 9 demonstrates that influence of the $E c$ on the profile of temperature. It is observed that the temperature profile increases as the value of the $E c$ increases. The effects of Prandtl number on temperature profiles are shown in Figure 10. Prandtl number can be used to increase the rate of cooling conducting fluids. Prandtl number signifies the ratio of momentum diffusivity to thermal diffusivity. Temperature is found to decrease with increasing $\operatorname{Pr} . \operatorname{Pr}=1$, indicates that the velocity boundary layer and thermal boundary layer are approximately equal.

Figure 11 displays the effect of thermal radiation of the temperature profiles. From this we observe that the temperature increases with increasing value of the parameter Nr. Figure 12 shows that the effect of Soret on concentration profile. An increase in the Soret number increases the concentration and the boundary layer thickness. It is observed that the concentration profile increases as the $\mathrm{Sr}$ increases.

Figures 13-15 explain the effects of the $X$-location on the velocity, temperature and concentration profiles. From Figure 13, it is observed that the velocity profile decreases with an increase in $X$ in the boundary layer. Figure 14 depicts that as the value of $X$ increases, the temperature increases. The concentration profile increases with as increasing the value of $X$.

The effect of $D_{f}$ on temperature profile is depicted in Figure 16. The temperature profile increases as $D_{f}$ increases. Figure 17 displays the nature of concentration profiles for various values of chemical reaction

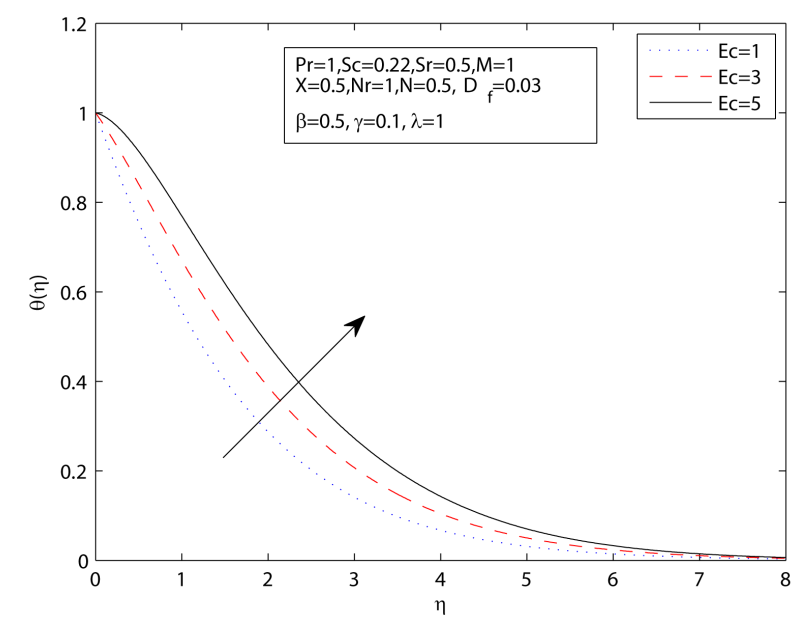

Figure 9. Temperature profile for various values of Eckert number $E c$.

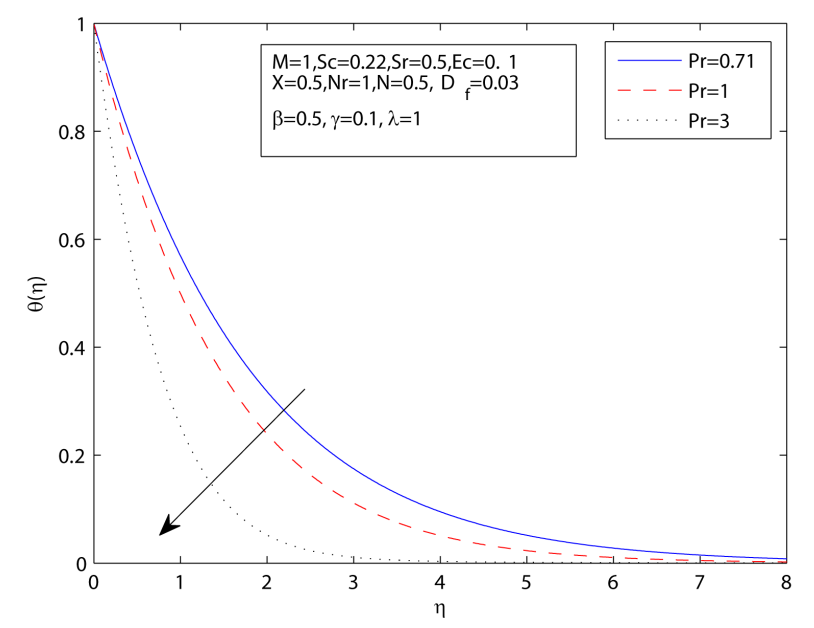

Figure 10. Temperature profile for various values of number $\operatorname{Pr}$. 


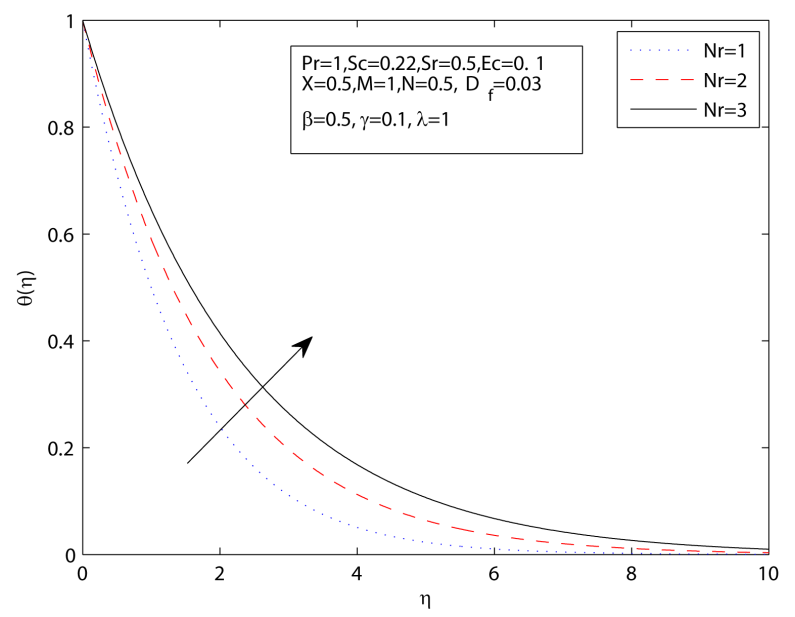

Figure 11. Temperature profile for various values of radiation parameter $\mathrm{Nr}$.

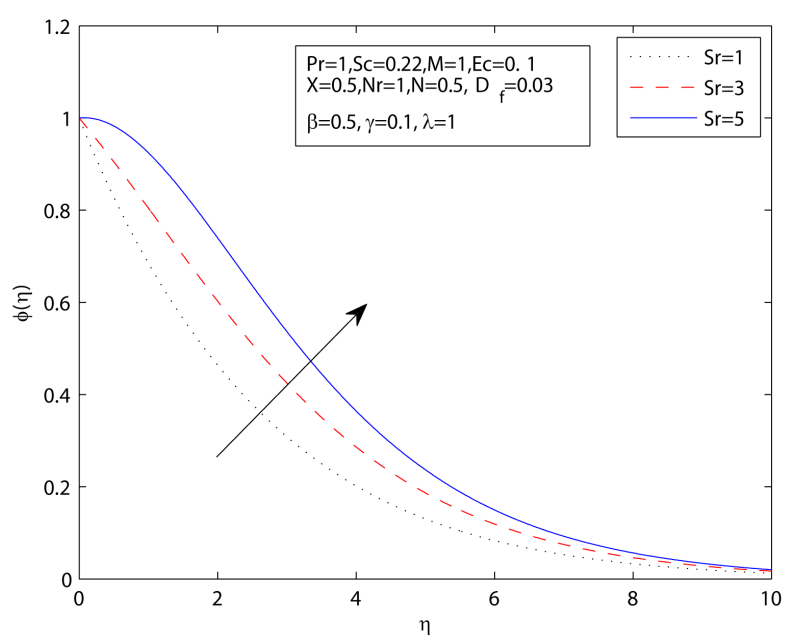

Figure 12. Concentration profile for various values of Soret number $\mathrm{Sr}$.

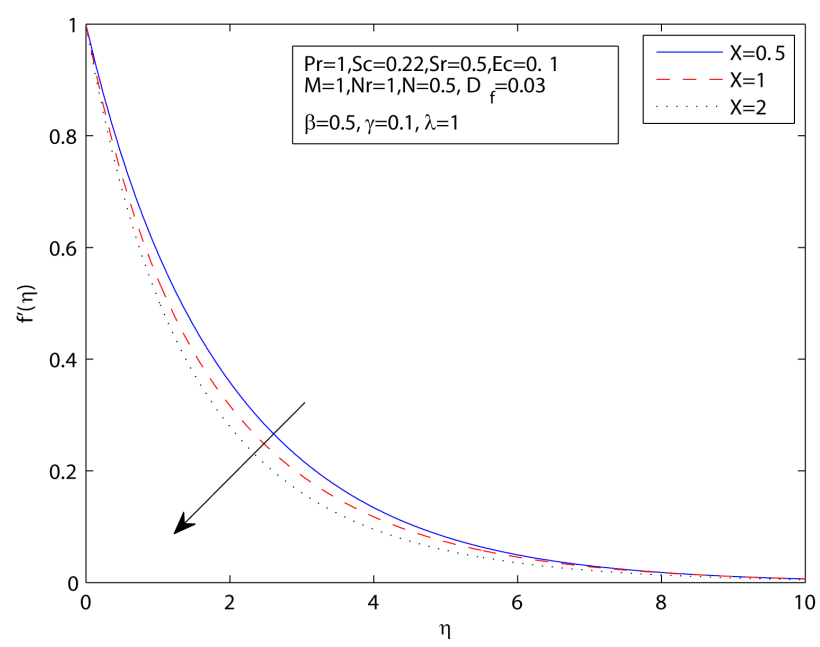

Figure 13. Velocity profile for various values of $X$-location. 


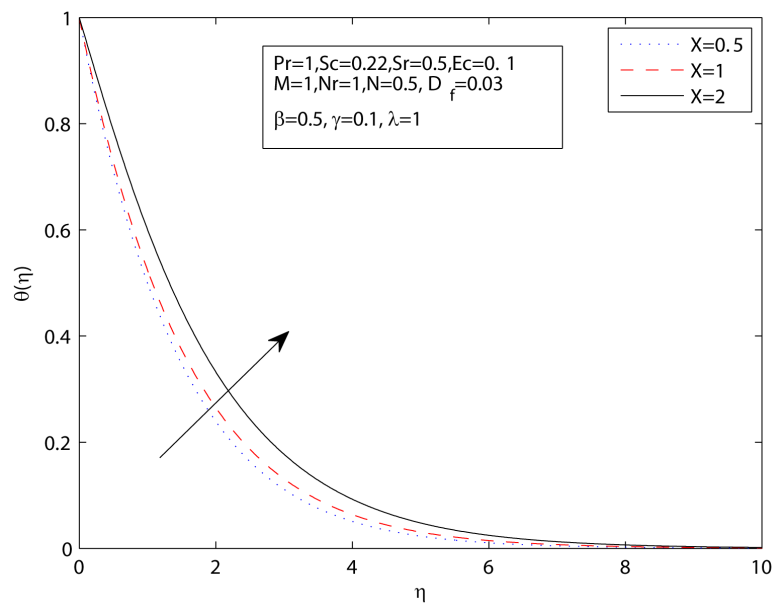

Figure 14. Temperature profile for various values of $X$-location.

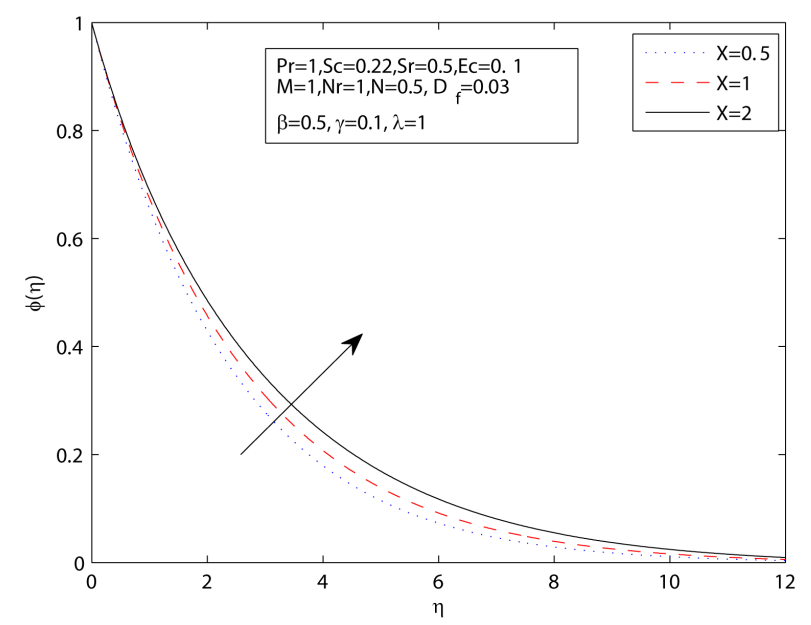

Figure 15. Concentration profile for various values of $X$-location.

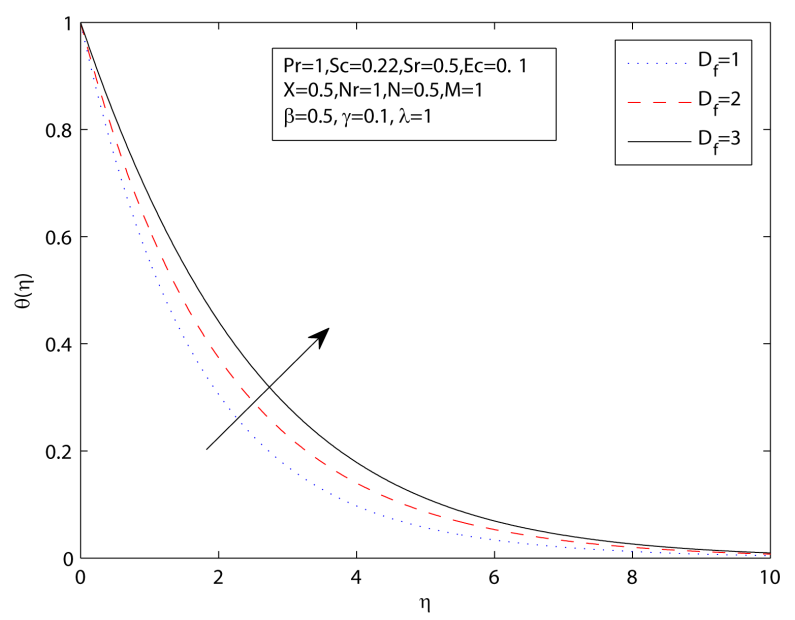

Figure 16. Temperature profile for various values of Dufour number $D_{f}$. 


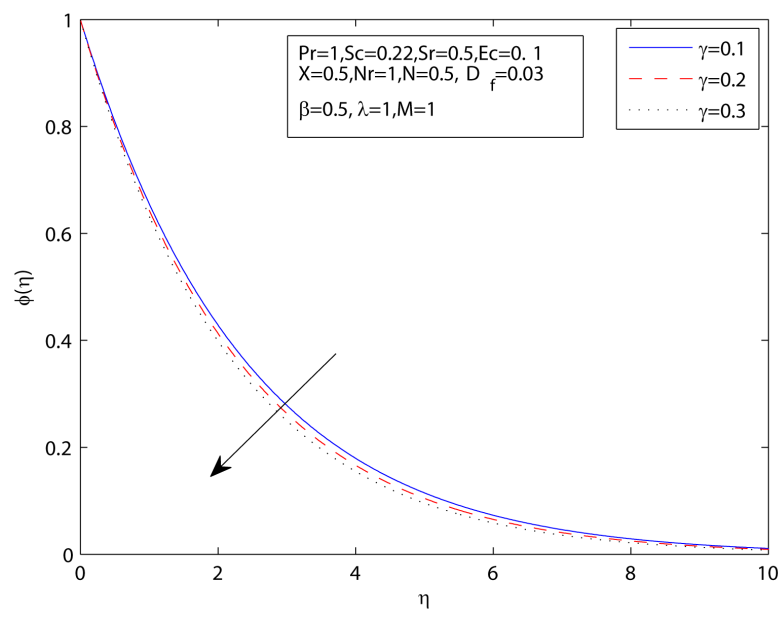

Figure 17. Concentration profile for various values of chemical reaction parameter $\gamma$.

parameter $\gamma$. Chemical reaction increases the rate of interfacial mass transfer and reduces the local concentration. Therefore the concentration profile decreases with an increase of the parameter $\gamma$.

\section{Conclusions}

The numerical solutions for MHD mixed convection flow of a Casson fluid over an exponentially stretching surface with Soret and Dufour, thermal radiation, chemical reaction are analyzed. The results are presented graphically with various parameters and the values are agreed with previously published work. From the graphical representations, we have the following observations:

- The effect of Casson fluid parameter when treated as fluid with variable plastic dynamic viscosity, the velocity profile decreases, temperature and concentration distributions are increased.

- The temperature increases with increasing values of the radiation parameter and Dufour number $D_{f}$.

- An increase in the mixed convection parameter $\lambda$ increases the velocity profiles, and decreases the temperature profiles and concentration profiles.

- An increase in the $X$-location reduces the non-dimensional velocity increase in the temperature and concentration distribution.

- With increasing values of chemical reaction parameter $\gamma$, the velocity profile decreases.

An increase in the Soret number increases the concentration profile and the boundary layer thickness.

\section{References}

[1] Garnier, M. (1962) Magneto Hydrodynamics in Materials Processing. Philosophical Transactions of the Royal Society A, 344, 249-263. http://dx.doi.org/10.1098/rsta.1993.0090

[2] Sakiadas, B.C. (1961) Boundary-Layer Behavior on Continuous Solid Surfaces. AIChE Journal, 7, $26-28$. http://dx.doi.org/10.1002/aic.690070108

[3] Crane, L.J. (1970) Flow Past a Stretching Plate. Zeitschrift für Angewandte Mathematik und Physik, 21, 590-595. http://dx.doi.org/10.1007/BF01587695

[4] Magyari, E. and Keller, B. (1999) Heat and Mass Transfer in the Boundary Layers on an Exponentially Stretching Continuous Surface. Journal of Physics D, 32, 577-585. http://dx.doi.org/10.1088/0022-3727/32/5/012

[5] Bidin, B. and Nazar, R. (2009) Numerical Solution of the Boundary Layer Flow over an Exponentially Stretching Sheet with Thermal Radiation. European Journal of Scientific Research, 33, 710-717.

[6] Sajid, M. and Hayat, T. (2008) Influence of Thermal Radiation on the Boundary Layer Flow Due to an Exponentially Stretching Sheet. International Communications in Heat and Mass Transfer, 35, 347-356. http://dx.doi.org/10.1016/j.icheatmasstransfer.2007.08.006

[7] Merrill, F.W. (1965) Rheology of Human Blood and Some Speculations on Its Role in Vascular Homeostatics Biomechanical Mechanisms in Vascular Homeostatics and Intravascular Thrombosis. In: Sawyer, P.N., Ed., Appleton Cen- 
tury Crofts, New York, 127-137.

[8] MacDonald, D.A. (1979) On Study Flow through Modelled Vascular Stenoses. Journal of Biomechanics, 12, 13-20. http://dx.doi.org/10.1016/0021-9290(79)90004-6

[9] Nadeem, S., Haq, R.U. and Lee, C. (2012) MHD Flow of a Casson Fluid over an Exponentially Shrinking Sheet. Scientia Iranica, 19, 1550-1553. http://dx.doi.org/10.1016/j.scient.2012.10.021

[10] Mukhopadhyay, S., De Ranjan, P., Bhattacharyya, K. and Layek, G.C. (2013) Casson Fluid Flow over an Unsteady Stretching Surface. Ain Shams Engineering Journal, 4, 933-938.

[11] McGregor, J.L. (1970) The Application of the Minimal Energy Hypothesis to a Casson Fluid. Bulletin of Mathematical Bio Physics, 32, 249-262. http://dx.doi.org/10.1007/BF02476889

[12] Partha, M.K., Murthy, P.V.S.N. and Rajasekhar, G.P. (2005) Effect of Viscous Dissipation on the Mixed Convection Heat Transfer from an Exponentially Stretching Surface. Heat and Mass Transfer, 41, 360-366. http://dx.doi.org/10.1007/s00231-004-0552-2

[13] Pal, D. (2010) Mixed Convection Heat Transfer in the Boundary Layers on an Exponentially Stretching Surface with Magnetic Field. Applied Mathematics and Computation, 217, 2356-2369. http://dx.doi.org/10.1016/j.amc.2010.07.035

[14] Kafoussias, N.G. and Williams, E.M. (1995) Thermal-Diffusion and Diffusion-Thermo Effects on Mixed Free-Forced Convective and Mass Transfer Boundary Layer Flow with Temperature Dependent Viscosity. International Journal of Engineering Science, 33, 1369-1384.

[15] Dursunkaya, Z. and Worek, Z.W. (1992) Diffusion Thermo and Thermal Diffusion Effects in Transient and Steady Natural Convection from a Vertical Surface. International Journal of Heat and Mass Transfer, 35, 2060-2065. http://dx.doi.org/10.1016/0017-9310(92)90208-A

[16] Afify, A.A. (2009) Similarity Solution in MHD Effects of Thermal Diffusion and Diffusion-Thermo on Free Convective Heat and Mass Transfer over a Stretching Surface Considering Suction or Injection. Communication in Non-Linear Science and Numerical Simulation, 14, 2202-2214.

[17] Hayat, T., Shehzad, S.A. and Alsaed, A. (2012) Soret and Dufour Effects on MHD Flow of Casson Fluid. Applied Mathematics and Mechanics, 33, 1301-1312. http://dx.doi.org/10.1007/s10483-012-1623-6

[18] Alam, M.S. and Rahman, M.M. (2006) Dufour and Soret Effects on Mixed Convection Flow Past a Vertical Porous Flat Plate with Variable Suction. Nonlinear Analysis, Modeling and Control, 11, 3-12.

[19] Pramanik, S. (2014) Casson Fluid Flow and Heat Transfer Past an Exponentially Porous Stretching Surface in the Presence of Thermal Radiation. Ain Shams Engineering Journal, 5, 205-212. http://dx.doi.org/10.1016/j.asej.2013.05.003

[20] Shateyi, S. and Marewo, G.T. (2014) Numerical Analysis of MHD Stagnation Point Flow of Casson Fluid, Heat and Mass Transfer over a Stretching Sheet. Proceedings of the 7th International Conference on Finite Differences, Finite Elements, Finite Volumes, Boundary Elements, Gdansk, 15-17 May 2014, 128-132.

[21] Ishak, A. (2011) MHD Boundary Layer Flow Due to an Exponentially Stretching Sheet with Radiation Effect. Sains Malaysiana, 40, 391-395.

[22] Mukhopadhyay, S. (2013) Effects of Thermal Radiation on Casson Fluid Flow and Heat Transfer over an Unsteady Stretching Surface Subjected to Suction/Blowing, Chinese Physics B, 22, Article ID: 114702. http://dx.doi.org/10.1088/1674-1056/22/11/114702

[23] Shehzad, S.A. and Hayat, T. (2013) Effects of Mass Transfer on MHD Flow of Casson Fluid with Chemical Reaction. Brazilian Journal of chemical Engineering, 30, 187-195. http://dx.doi.org/10.1590/S0104-66322013000100020

[24] Cebeci, T. and Bradshaw, P. (1984) Physical and Computational Aspects of Convective Heat Transfer. Springer, Berlin Heidelberg. http://dx.doi.org/10.1007/978-3-662-02411-9 